\title{
Unidirectional Protection Strategy for Multi-terminal HVDC Grids
}

\author{
Ataollah Mokhberdoran, Nuno Silva, Helder Leite and Adriano Carvalho
}

\begin{abstract}
Protection issue is identified as the main drawback of emerging multi-terminal HVDC grids. Multi-terminal HVDC grid demands fast short circuit fault current interruption. Fast DC circuit breakers as a promising solution can be implemented as either bidirectional or unidirectional devices. In addition to less implementation cost, the unidirectional DC circuit breakers have less power losses as compared to the bidirectional devices. A protection strategy for multi-terminal HVDC grid based on the unidirectional breaking devices is discussed and assessed in this paper. The performance of unidirectional protection strategy is examined under different fault scenarios in a detailed fourterminal MMC-HVDC grid model. Furthermore, the impacts of unidirectional protection strategy on power converters and also current interruption and surge arrester ratings of the DC circuit breakers are discussed.
\end{abstract}

Index Terms-DC circuit breaker, HVDC, Protection Device, Voltage Source Converter (VSC), Short-circuit.

\section{INTRODUCTION}

$\mathbf{I}$ NCREASING penetration of the clean energy resources has led to a demand for development of more efficient ways to transmit bulk amount of electrical energy over long distances. As a solution, high voltage direct current (HVDC) transmission technology has been employed by different project developers. Large offshore wind farms and onshore AC systems can be interconnected through multi-terminal HVDC (MT-HVDC) grid in order to share the harvested energy between various geographical areas and enhance the system reliability [1].

Voltage source converter (VSC) offers several technical benefits for application in the future MT-HVDC grid. The VSC technology was introduced by conventional two-level converter and has evolved into multilevel converter topologies [2]. Introduction of modular multilevel converter (MMC) paved the way for the application of VSC in HVDC transmission systems. Recently, different variants of the half-bridge MMC have been developed and employed in HVDC industry [3]. The conventional VSCs and the half-bridge MMC topologies are highly vulnerable against DC side short circuit fault due to behavior of IGBTs' antiparallel diodes. Although full-bridge MMCs and other fault-tolerant converters can solve this issue, their power losses and lack of protection selectivity have been identified as their application drawbacks. Moreover, these converters have not been tested practically in full-scale, yet [1].

The research leading to these results has received funding from the People Programme (Marie Curie Actions) of the European Unions Seventh Framework Programme (FP7/2007-2013) under REA grant n 317221.

Ataollah Mokhberdoran and Nuno Silva are with EFACEC Energia, S.A, Un. Switchgear and Automation, Rua Frederico Ulrich, PO Box 3078 4471907, Maia, Portugal (e-mail: mokhber@fe.up.pt). Ataollah Mokhberdoran, Helder Leite and Adriano Carvalho are with the Department of Electrical and Computer Engineering of University of Porto, Portugal.
HVDC circuit breaker (DCCB) as a promising solution may solve the protection problem in the MT-HVDC grids [1], [4], [5], [6]. Fast DCCBs can be categorized as hybrid DC circuit breakers (HCBs) and solid-state DC circuit breakers (SSCBs). The SSCBs can interrupt the fault current in tens of microseconds whereas the interruption time in HCB is expected to be less than $3 \mathrm{~ms}$ [4], [5], [3]. Although the HCB interrupts the current fast enough and has acceptable power losses, its realization cost for MT-HVDC grid can be expensive due to the large number of required semiconductor switches [7].

DCCBs are usually considered to be bidirectional and hence interrupt the current in their forward and backward directions [4]. Unidirectional DCCBs (UCBs) conduct the current in their forward and backward directions whereas interrupts the current only in one direction. The application of a unidirectional SSCB in a point-to-point $\mathrm{DC}$ connection is investigated in [8] and a unidirectional current releasing DCCB has been proposed in [9]. The protection of radial offshore DC grid using UCBs has also been studied [10]. The main concern regarding the application of UCB in the MT-HVDC grid is its inability in interrupting the fault current flowing in its backward direction as it may occur in a DC bus short circuit fault scenario.

In this paper, a protection strategy based on the unidirectional HCBs (UHCB) is suggested for MT-HVDC grid. The suggested strategy tries to overcome the main drawback of UHCB. Protection logics for DC bus and transmission line faults are investigated. The performance of suggested strategy is examined through different fault scenarios in a four-terminal HVDC grid model. For DC bus fault scenario, two DCCB tripping schemes are considered. Moreover, the superiorities and limitations of unidirectional protection of the MT-HVDC grid are assessed. The impacts of suggested strategy on the MT-HVDC grid elements and the HCB are also studied.

\section{TYPICAL PROTECTION STRATEGY}

Three different protection strategies for the MT-HVDC grids are identified: 1) handshaking approach with AC breakers, 2) fault-tolerant converters with disconnector switches, 3) fast fault identification relays with fast DCCBs [1]. In this paper, the third protection strategy together with the HCBs are considered. The HCBs can be placed at ends of each transmission line and also at DC side of converters. Fig. 1 shows the typical bidirectional DCCBs (BCBs) arrangement and the protection zones in a three-terminal HVDC grid. $\mathrm{CB}_{x y}$ represents the DCCB attached to line $\mathrm{L}_{x y}$ close to bus $\mathrm{B}_{x}$. Also, $\mathrm{CB}_{x x}$ represents the DCCB attached to $\mathrm{VSC}_{x}$ at bus $\mathrm{B}_{x}$.

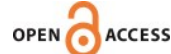




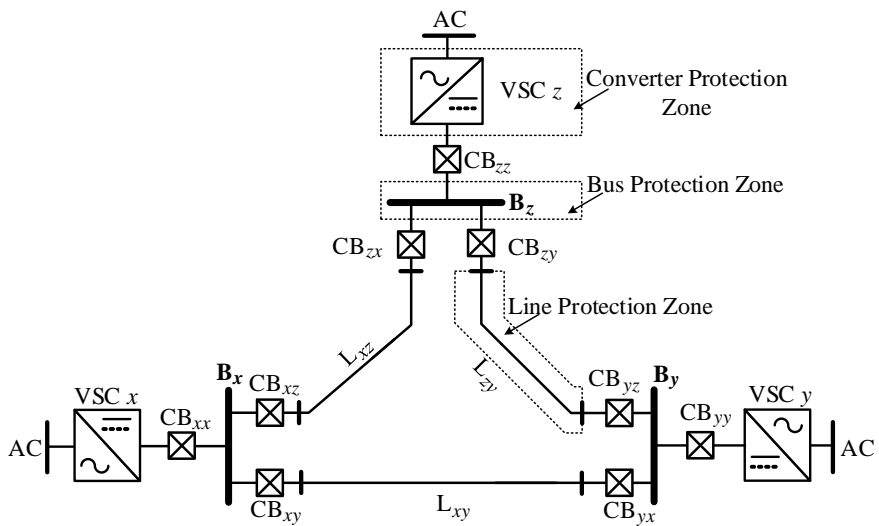

Fig. 1. BCBs arrangement in a multi-terminal HVDC grid

\section{A. DC Bus Fault}

Typically, a DC bus is protected by bus differential protection scheme. In the DC bus, sum of all incoming and outgoing currents must be zero. If a short circuit fault occurs at the DC bus, the sum of incoming and outgoing currents becomes nonzero. Therefore, DC bus trip signal can be generated if the sum of currents exceeds a near zero value. The differential protection scheme is quite fast and selective due to its low computing burden. The fault clearance in the DC bus zone can be done by opening all adjacent DCCBs. If the DC bus is connected to a converter, the converter DCCB should also be opened. Assume $n$ transmission lines are connected to bus $\mathrm{B}_{x}$. The protection logic can be given as (1).

$$
\text { Fault at } \mathrm{B}_{x} \Rightarrow \operatorname{Trip}\left(\mathrm{CB}_{x 1}, \ldots, \mathrm{CB}_{x x}, \ldots, \mathrm{CB}_{x n}\right)
$$

\section{B. Transmission Line Fault}

When using fast protection schemes transmission line cannot be protected by differential protective relays due to communication delay. Therefore, the transmission line is protected by communication-less non-unit protection schemes [11]. The non-unit protection schemes rely on local measurement of current, voltage, current derivative, voltage derivative or their combination [1]. If a fault is detected on the line, both DCCBs of faulty line should trip. The protection logic can be given as:

$$
\text { Fault on } \mathrm{L}_{x y} \Rightarrow \operatorname{Trip}\left(\mathrm{CB}_{x y}, \mathrm{CB}_{y x}\right)
$$

\section{UNIDIRECTIONAL PROTECTION STRATEGY}

Fig. 22a) depicts the arrangement of UCBs in a threeterminal HVDC grid. The arrow in UCB symbol shows its current interruption direction. A protection strategy covering the DC bus and the transmission line zones based on the UCBs is suggested for the meshed HVDC grids in this section.

\section{A. DC Bus Fault}

Fig. 2(a) shows the fault currents during a short circuit fault at DC bus $\mathrm{B}_{z}$. Three fault currents flow though three adjacent UCBs. Since the fault current $i_{F z z}$ flows in the forward direction of $\mathrm{CB}_{z z}$, it can be interrupted by $\mathrm{CB}_{z z}$. Fault
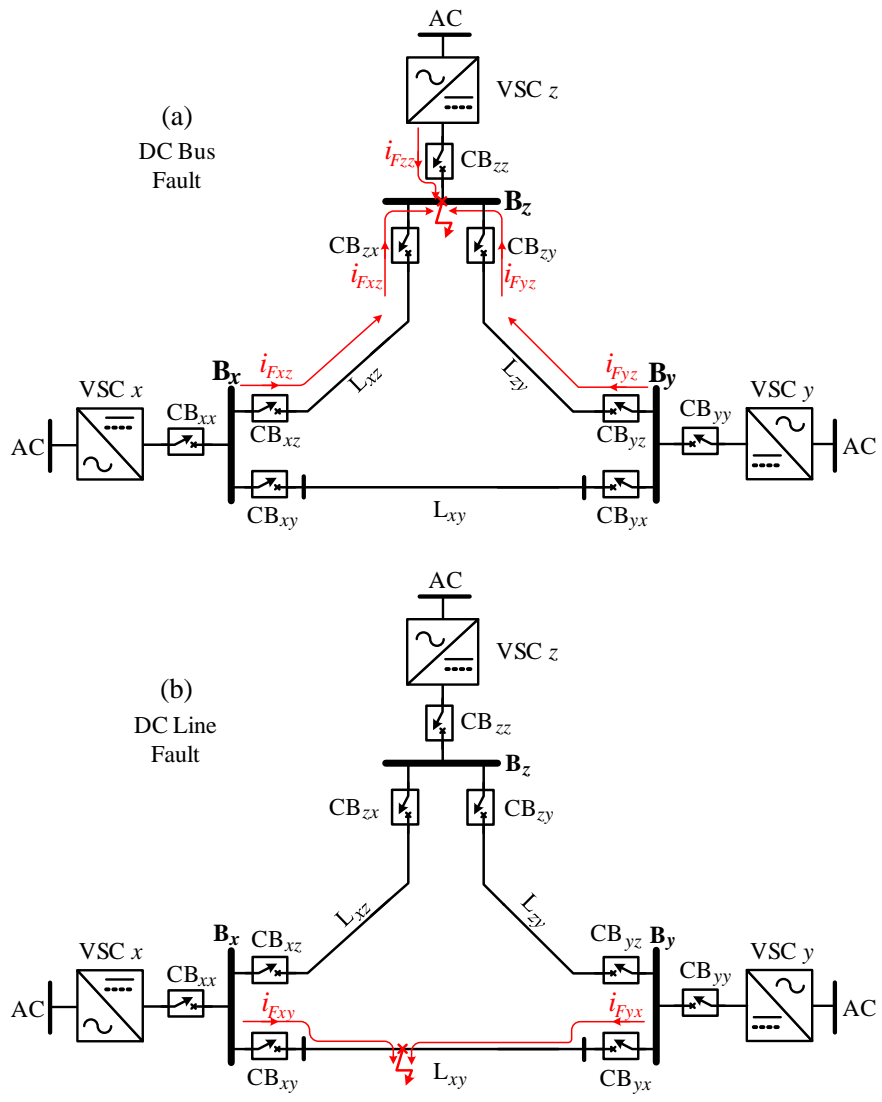

Fig. 2. UHCBs arrangement and directions and fault current directions (a) DC bus fault, (b) DC transmission line fault

currents $i_{F x z}$ and $i_{F y z}$ flow through the adjacent lines to the fault location and are in the backward directions of $\mathrm{CB}_{z x}$ and $\mathrm{CB}_{z y}$ and cannot be interrupted by them.

As shown in Fig. 2(a), $i_{F x z}$ flows in the forward direction of $\mathrm{CB}_{x z}$ and can be interrupted by this UCB, which is placed at the remote end of line. Any other fault current flowing from the adjacent lines can be interrupted by the remote UCB. The protection logic for the DC bus fault can be given by:

$$
\text { Fault at } \mathrm{B}_{x} \Rightarrow \operatorname{Trip}\left(\mathrm{CB}_{1 x}, \ldots, \mathrm{CB}_{x x}, \ldots, \mathrm{CB}_{n x}\right)
$$

The trip command for remote DCCB can be generated locally or communicated between two buses. In the communicationbased method, fault detection is done locally in the faulted bus and the trip command is communicated to the remote DCCBs. On the other hand, the communication-less method relies on the fault detection at the remote buses. A fault at $\mathrm{B}_{x}$ can be detected by the remote DCCBs at the other buses of system either based on the non-unit protection or overcurrent protection schemes .

\section{B. Transmission Line Fault}

Fig. 2(b) shows a short circuit fault in line $\mathrm{L}_{x y}$. Two fault currents flow from both ends of the transmission line into the fault location. In any line fault condition, the fault currents flow in the forward directions of corresponding UCBs. Therefore, the fault can be cleared by opening the corresponding 

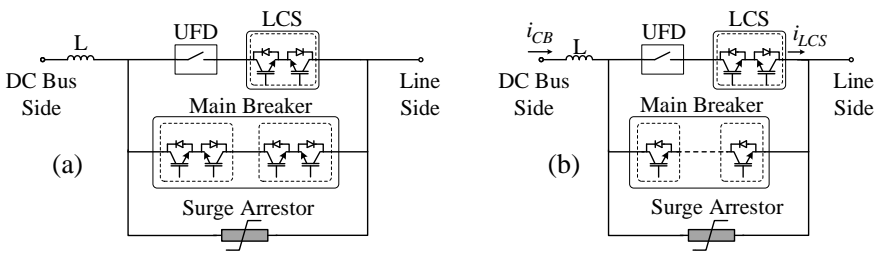

Fig. 3. Hybrid DC circuit breaker (a) typical HCB, (b) UHCB

UCBs. Unidirectional protection logic for transmission line fault is similar to (2).

\section{HYBRID DC CIRCUIT BREAKER}

\section{A. Typical Hybrid DC Circuit Breaker}

The configuration of a typical HCB is depicted in Fig. 3 [a) [12]. The main current conduction path contains a fast mechanical disconnector switch (UFD) in series with the load commutation switch (LCS) [5], [12]. The LCS is not required to block the nominal voltage and therefore, it has a lower voltage rating and can be realized by series connection of few semiconductor switches. Hence, the HCB has reasonable power dissipation whereas it is able to interrupt DC fault current quickly (around $2.5 \mathrm{~ms}$ ) [5]. The parallel solid-state branch is the main breaker unit (MBU) during the fault condition. Voltage rating of the main breaker unit can be identified based on the transient recovery voltage (TRV) of the circuit breaker, which is usually limited by the reference voltage of surge arrester branch [12]. In order to allow bidirectional current flow and also bidirectional fault current interruption the semiconductor switches are connected in anti-series.

\section{B. Unidirectional Hybrid DC Circuit Breaker}

The topology of a unidirectional hybrid DC circuit breaker (UHCB) for the positive pole of HVDC system is depicted in Fig. 3 (b). In the UHCB topology, two anti-series semiconductor switches are replaced by one switch. Therefore, the UHCB is only able to interrupt the fault current in the transmission line side. The normal power flow can be maintained in both forward and backward directions due to presence of antiparallel diodes. The UHCB requires half the number of semiconductor switches in its MBU as compared to the typical HCB [13].

The operation principles of UHCB for the transmission line fault are similar to the typical HCB. However, due to conduction of antiparallel diodes in the LCS unit of UHCB, similar operation sequence cannot be applied for the DC bus fault. Suggested operation flowchart for the UHCB is shown in Fig. 14. In the flowchart, $i_{L C S}$ and $i_{C B}$ represent the LCS unit current and UHCB current as it is illustrated in Fig. 3 b). In case of a line fault $i_{L C S}$ is positive and therefore UHCB can activate the MBU for fault interruption. When $i_{L C S}$ is negative, it means that the fault current flows in the backward direction of the UHCB. This case happens for UHCBs attached to a faulty DC bus. In this case, the LCS unit should be opened and commutate whole the fault current into the antiparallel diodes of MBU. Thereafter, the UFD can be opened. Note

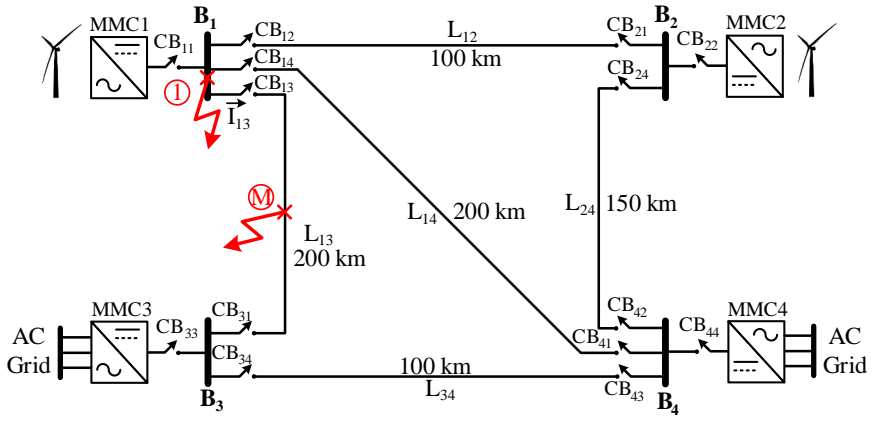

Fig. 4. Test multi-terminal HVDC grid
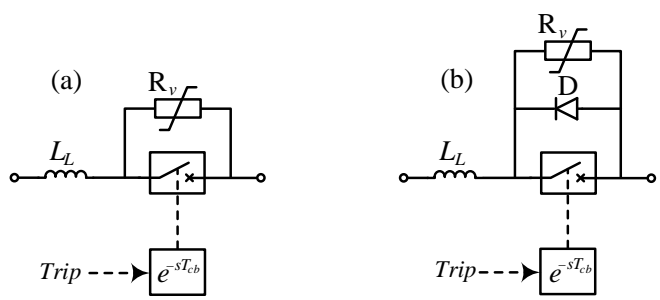

Fig. 5. Aggregated models (a) typical HCB, (b) UHCB

that the UHCB still conducts the fault current in its backward direction through the antiparallel diodes of MBU until the fault current is interrupted by the remote UHCB.

\section{Test System}

\section{A. Meshed HVDC Grid}

A four-terminal meshed HVDC grid model, which was proposed in [14] is used in this study. The system configuration is shown in Fig. 4. The studied model represents a cable-based meshed HVDC grid. The investigated system has a symmetric monopole HVDC configuration and includes four half-bridge MMCs. The MMCs are modeled by a continuous modeling approach with antiparallel diodes representing the blocking capability of the MMCs [14].

In the normal condition, MMCs 1 and 2 inject almost 700 MW into the grid and MMCs 3 and 4 absorb 600 and 800 MW, respectively. The blocking current threshold of MMCs is set to $3.2 \mathrm{kA}$ in order to observe the MMC behavior without blocking during sever fault conditions. The parameters of fourterminal grid are illustrated in Table II

\section{B. DC Cable}

HVDC transmission lines are modeled based on the XLPE insulated cable using frequency dependent modeling approach. The cable cross-sections and properties of material are illustrated in Fig. 15] and Table III] respectively [15].

\section{Circuit Breaker Model}

Since the internal operation of DCCB is not the subject of this paper, the aggregated models of $\mathrm{HCB}$ and UHCB are used. Fig. 5(a) and (b) depict the aggregated models of $\mathrm{HCB}$ and UHCB, respectively. As shown in Fig. 5(b) the UHCB model is derived from HCB model by adding one 

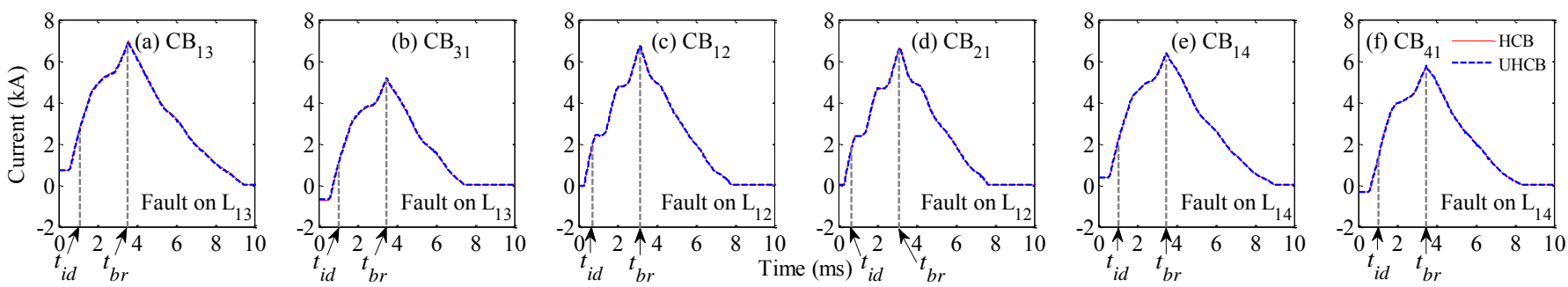

Fig. 6. Fault current for fault at middle of transmission line for BCBs and UCBs (a) fault on $\mathrm{L}_{13}, \mathrm{CB}_{13}$ current, (b) fault on $\mathrm{L}_{31}, \mathrm{CB}_{31}$ current, (c) fault on $\mathrm{L}_{12}, \mathrm{CB}_{12}$ current, (d) fault on $\mathrm{L}_{21}, \mathrm{CB}_{21}$ current, (e) fault on $\mathrm{L}_{14}, \mathrm{CB}_{14}$ current, (e) fault on $\mathrm{L}_{41}, \mathrm{CB}_{41}$ current
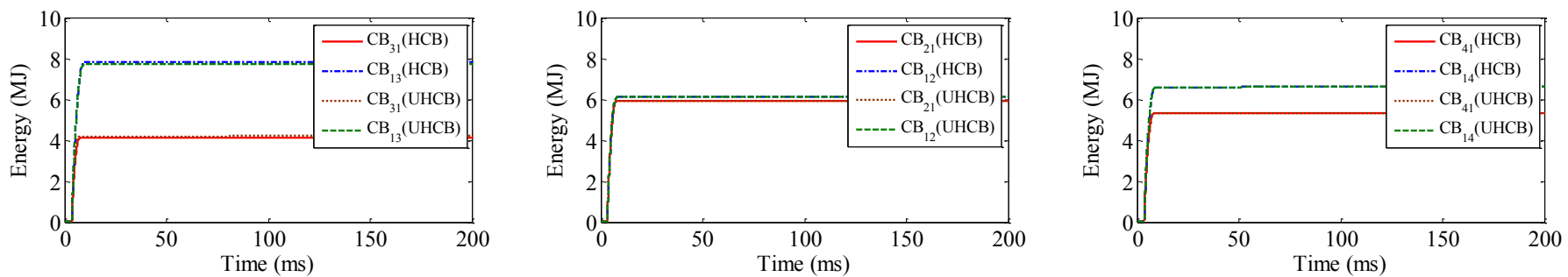

Fig. 7. Absorbed energy in surge arresters of $\mathrm{BCBs}$ and $\mathrm{UCBs}$ (a) $\mathrm{CB}_{13}$ and $\mathrm{CB}_{31}$, (b) $\mathrm{CB}_{12}$ and $\mathrm{CB}_{21}$, (c) $\mathrm{CB}_{14}$ and $\mathrm{CB}_{41}$

parallel diode (D). The $L_{L}, R_{v}$ and $T_{c b}$ represent the limiting inductor, surge arrester and the circuit breaker operation time delay, respectively. The value of limiting inductor $\left(L_{L}\right)$ of the line DCCBs is set to $100 \mathrm{mH}$. The $L_{L}$ for the converter station DCCBs is set to $10 \mathrm{mH}$. The reference voltage of surge arresters is set to $480 \mathrm{kV}$. The HCB operation delay $\left(T_{c b}\right)$ is set to $2.5 \mathrm{~ms}$, which includes time delays in the LCS, UFD and MBU operations [5]. The trip command is received by the DCCB and breaker component interrupts the current independent of its value after a time delay equal to $T_{c b}$.

\section{Protection system}

The system performance is studied based on the typical and the suggested unidirectional protection strategies.

1) Typical protection strategy: A non-unit scheme, which has recently been proposed in [11] is employed for transmission line protection. The utilized method uses the local current measurements for line fault detection. The DC bus fault is detected by the differential protection scheme. The DC bus trip signal for fault is generated locally in typical protection strategy.

2) Unidirectional protection strategy: The mentioned nonunit scheme is also used in the unidirectional protection strategy. Two different schemes for the DC bus fault detection are considered in the unidirectional protection strategy: 1) local fault detection (communication-based), 2) remote overcurrent fault detection (communication-less).

In the first method a bus fault is detected by the bus differential relay and the trip command is communicated to the remote UHCBs. Communication time is modeled by a time delay block. In the second method a communication-less system is considered. The bus fault is detected at the remote healthy buses when the line current exceeds specific threshold.
TABLE I

TRIP TIMES OF DIFFERENT TYPES OF DC CIRCUIT BREAKERS FOR DC BUS AND TRANSMISSION LINE FAULTS

\begin{tabular}{ccccccccc}
\hline \hline \multirow{2}{*}{ DCCB } & \multicolumn{8}{c}{ Trip time $\left(\boldsymbol{t}_{\boldsymbol{i d}}\right)[\mathrm{ms}]$} \\
\cline { 2 - 10 } & \multicolumn{2}{c}{ Fault at $\mathbf{B}_{1}$} & \multicolumn{2}{c}{ Fault on $\mathbf{L}_{12}$} & \multicolumn{2}{c}{ Fault on $\mathbf{L}_{13}$} & \multicolumn{2}{c}{ Fault on $\mathbf{L}_{14}$} \\
\cline { 2 - 10 } & BCB & $\mathbf{U C B}$ & $\mathbf{B C B}$ & $\mathbf{U C B}$ & $\mathbf{B C B}$ & $\mathbf{U C B}$ & BCB & UCB \\
\hline $\mathrm{CB}_{11}$ & 0.1 & 0.1 & - & - & - & - & - & - \\
$\mathrm{CB}_{12}$ & 0.1 & 0.1 & 0.79 & 0.79 & - & - & - & - \\
$\mathrm{CB}_{21}$ & 5 & 1.5 & 0.66 & 0.66 & - & - & - & - \\
$\mathrm{CB}_{13}$ & 0.1 & 0.1 & - & - & 1.05 & 1.05 & - & - \\
$\mathrm{CB}_{31}$ & 10 & 2 & - & - & 0.95 & 0.95 & - & - \\
$\mathrm{CB}_{14}$ & 0.1 & 0.1 & - & - & - & & 1.05 & 1.05 \\
$\mathrm{CB}_{41}$ & 10 & 2 & - & - & - & - & 0.95 & 0.95 \\
\hline
\end{tabular}

\section{Simulation}

The results from study of four fault scenarios are presented and compared in this section.

\section{A. Transmission line fault}

Transmission line fault is studied through three independent permanent pole-to-pole low impedance $\left(R_{\text {fault }}=100 \mathrm{~m} \Omega\right)$ short circuit faults at the middle of lines $\mathrm{L}_{12}, \mathrm{~L}_{13}, \mathrm{~L}_{14}$. The line fault is incepted at time $0 \mathrm{~s}$. As discussed in section III] the line fault clearing process for UCBs and BCBs are the same. Therefore, to clear the line fault from the system DCCBs at both ends of the faulted line should trip. Fig. 6(a)-(f) show the current in DCCBs for the short circuit fault in different transmission lines. The currents in HCB and UHCB are the same. $t_{i d x y}$ and $t_{b r x y}$ represent the fault identification time and the DCCB action time for $\mathrm{CB}_{x y}$, respectively. Note that the fault identification and the trip command generation are assumed to be simultaneous.

The numerical values of fault identification time are illustrated in Table I. Due to the longer length of $\mathrm{L}_{13}$ and $\mathrm{L}_{14}$, the midpoint fault is detected later than the similar fault in $\mathrm{L}_{12}$. Absorbed energy by the surge arrester of each DCCB is 

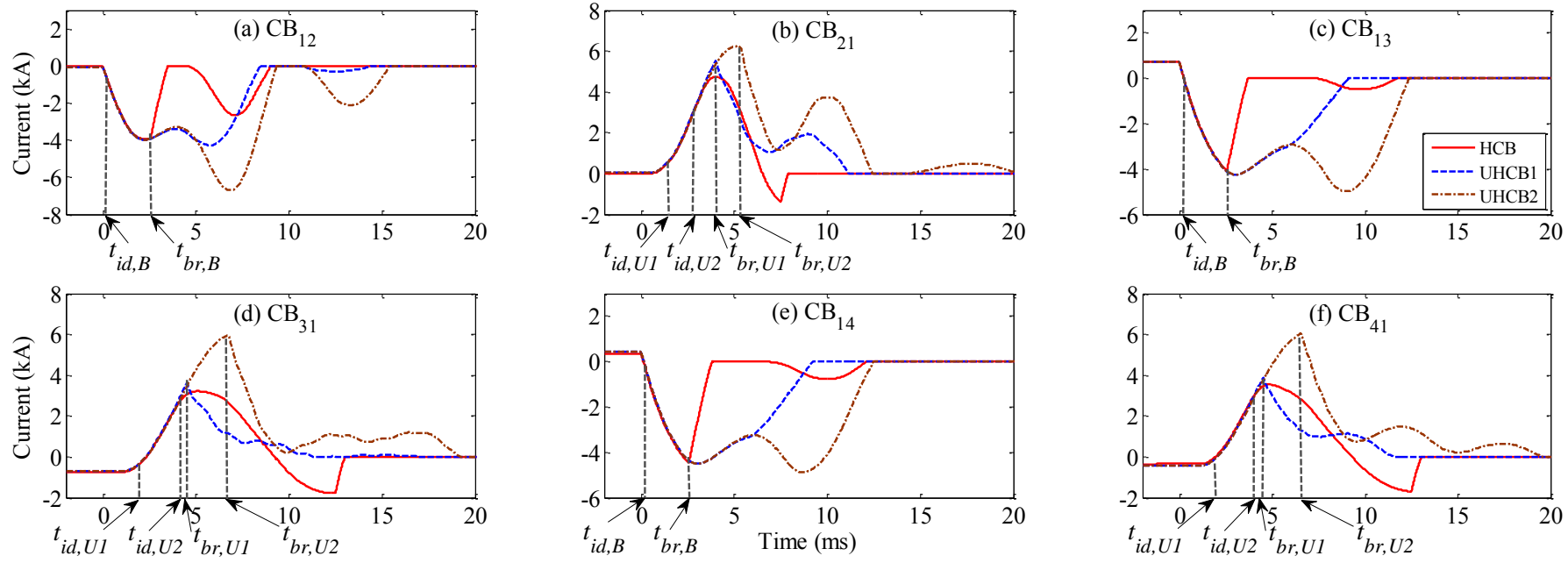

Fig. 8. Current in DCCB during fault at bus $\left(\mathrm{B}_{1}\right.$ ) for BCBs and UCBs (a) $\mathrm{CB}_{12}$, (b) $\mathrm{CB}_{21}$, (c) $\mathrm{CB}_{13}$, (d) $\mathrm{CB}_{31}$, (e) $\mathrm{CB}_{14}$, (f) $\mathrm{CB}_{41}$
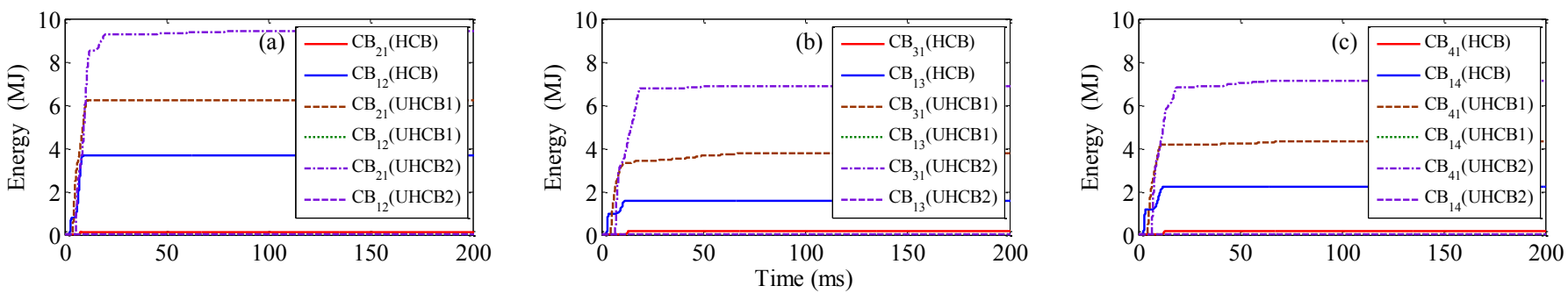

Fig. 9. Absorbed energy in surge arresters of $\mathrm{BCBs}$ and $\mathrm{UCBs}$ (a) $\mathrm{CB}_{12}$ and $\mathrm{CB}_{21}$, (b) $\mathrm{CB}_{13}$ and $\mathrm{CB}_{31}$, (c) $\mathrm{CB}_{14}$ and $\mathrm{CB}_{41}$

depicted in Fig. 7. The difference in dissipated energy in the surge arresters is due to unequal interrupted fault currents in corresponding DCCBs and also different fault distances from DCCB. DCCBs with positive pre-fault current (pre-fault and fault currents are in the same direction) reach higher current than the DCCB with negative pre-fault current and therefore, larger amount of energy is dissipated in their surge arresters.

\section{B. DC bus fault}

During a bus fault in the MT-HVDC grid, due to the low inductance between the converter and fault location, high fault current flows in the DC side of the converter. The fault current may exceed the self-protection threshold of the MMC and cause the MMC blocking. Protection of converter against DC bus faults can rely on either AC side circuit breaker or the converter station DCCB. In this study, the MMC is protected by a DCCB at its DC side. A permanent pole-to-pole low impedance $\left(R_{\text {fault }}=100 \mathrm{~m} \Omega\right)$ short circuit fault is incepted at bus $\mathrm{B}_{1}$ at time $0 \mathrm{~s}$. In the typical bidirectional strategy upon fault detection by the differential scheme, $\mathrm{CB}_{11}, \mathrm{CB}_{12}$, $\mathrm{CB}_{13}, \mathrm{CB}_{14}$ should trip and disconnect the adjacent lines from $B_{1}$. Therefore, terminal 1 of the MT-HVDC grid will be disconnected from rest of the system and consequently, the amount of harvested energy from generation nodes of system will be reduced. Hence, MMC 3 and 4 will absorb less power as compared to pre-fault conditions. The remote DCCBs of the adjacent lines trip after a longer time delay to disconnect the cables from healthy DC buses.

In the unidirectional protection strategy, upon fault detection at bus $\mathrm{B}_{1}$ all adjacent UHCBs including $\mathrm{CB}_{11}, \mathrm{CB}_{12}, \mathrm{CB}_{13}$, $\mathrm{CB}_{14}$ are opened. The fault currents flow in the backward directions of $\mathrm{CB}_{12}, \mathrm{CB}_{13}, \mathrm{CB}_{14}$ and these UHCBs are unable to interrupt the fault current. Therefore, based on $3, \mathrm{CB}_{21}, \mathrm{CB}_{31}$ and $\mathrm{CB}_{41}$ also should trip. The DC bus fault clearing is studied through two protection schemes as explained in subsection V-D2 In the communication-based method, communication delay is modeled by a time delay block. The time delay block represents sum of propagation and transmitter/receiver delays. The propagation delay is set to $5 \mu \mathrm{s} / \mathrm{km}$ and the transmitter/receiver delay is set to $1 \mathrm{~ms}$ [16]. The trip times of remote DCCBs are illustrated in Table \ The second method is an overcurrent protection scheme. The overcurrent thresholds are set to $3 \mathrm{kA}$ for all lines.

Fig. 8(a)-(f) show currents of all DCCBs attached to the adjacent lines for three discussed protective schemes. In Fig. 8 HCB, UHCB1 and UHCB2 represents the bidirectional, communication-based and overcurrent-based unidirectional protective schemes, respectively. In addition, $t_{i d}$ and $t_{b r}$ represent fault identification and current interruption times for each protective scheme. Absorbed energy in the surge arrester of each DCCB is depicted in Fig. 9 (a)-(c).

As can been in Fig. 8, current in $\mathrm{CB}_{21}, \mathrm{CB}_{31}$ and $\mathrm{CB}_{41}$ reach higher values in overcurrent-based scheme as compared to the communication-based scheme. As seen in Fig. 8(a), (c) and (e), the HCBs interrupt the bus fault current before 

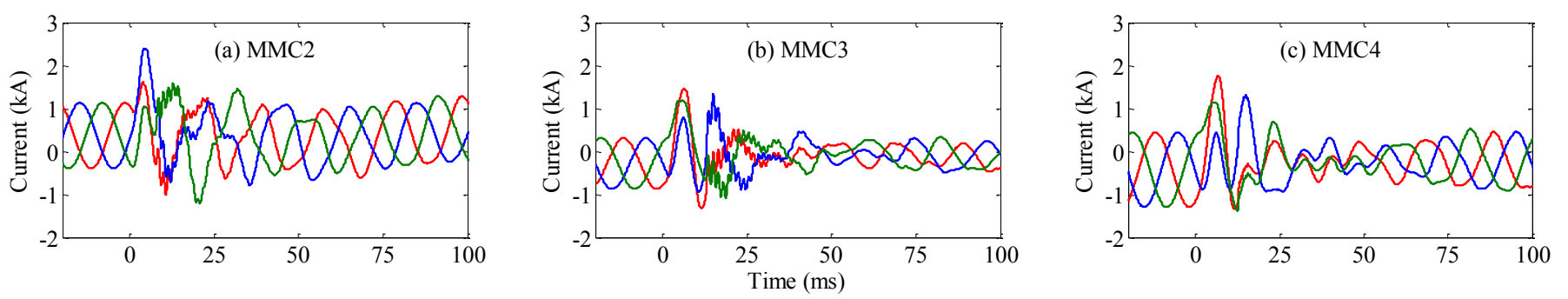

Fig. 10. The arm currents of MMCs in presence of BCBs (a) MMC2, (b) MMC3, (c) MMC4
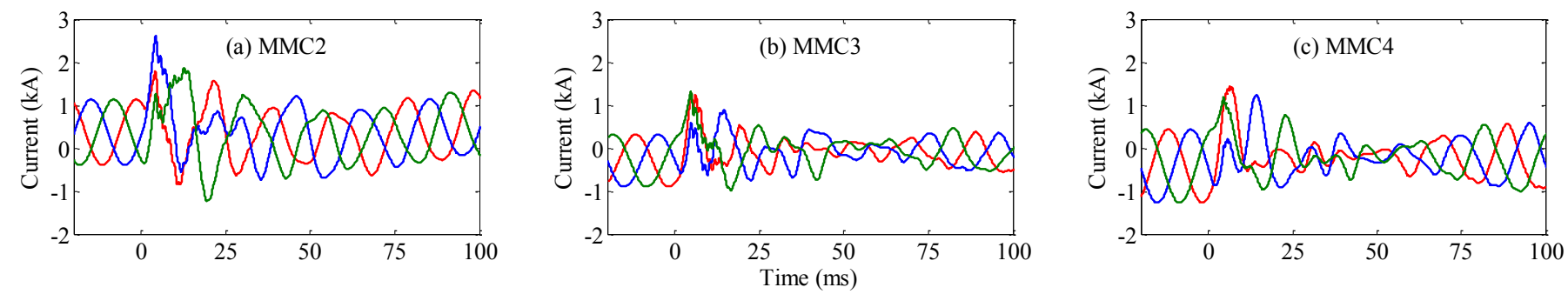

Fig. 11. The arm currents of MMCs in presence of UCBs (communication-based method) (a) MMC2, (b) MMC3, (c) MMC4
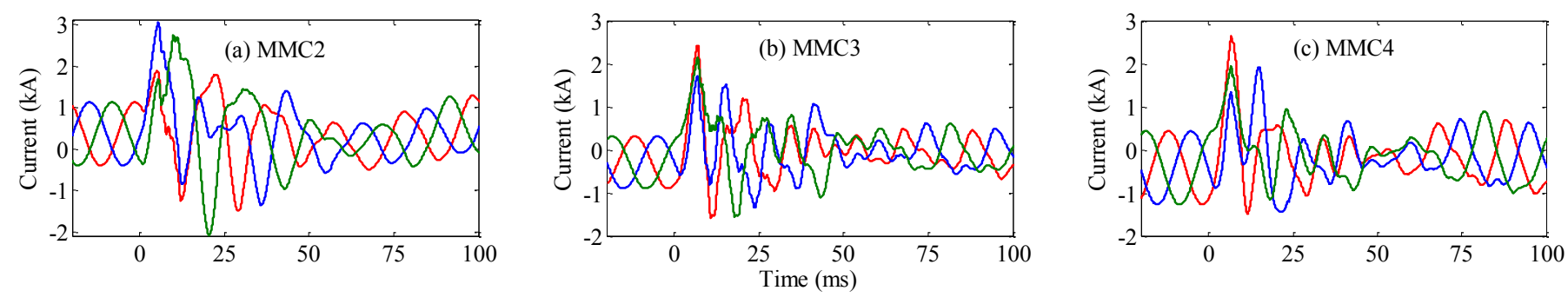

Fig. 12. The arm currents of MMCs in presence of UCBs (overcurrent-based method) (a) MMC2, (b) MMC3, (c) MMC4

reaching higher values. On the other hand, the remote UHCBs in the communication-based unidirectional protective scheme (UHCB1) also interrupt the bus fault current before reaching higher values. Due to higher interrupted current and larger cable inductance in unidirectional protection strategy, UHCBs' surge arresters absorb more energy than the HCBs.

Fig. 10] shows the MMC arm currents for healthy buses (MMC 2, 3 and 4) in presence of HCBs. In addition, the arm currents of MMC 2, 3 and 4 in presence of UHCBs for communicationbased scheme are depicted in Fig. 11. Also, the arm currents of mentioned MMCs in presence of UHCBs for overcurrentbased scheme are illustrated in Fig. 12. The arm currents of MMC 1 are not included since this converter is isolated from the MT-HVDC grid due to converter station DCCB $\left(\mathrm{CB}_{11}\right)$ action during the DC bus fault.

\section{DISCUSSION}

\section{A. Circuit breaker current rating}

The maximum current in possible fault scenarios sets the requirements for DCCB current interruption rating.

1) Communication-based method: Due to lower inductance of short transmission lines, rate of rise of fault current in short lines is higher as compared to the long lines. Hence, the remote DCCBs in short lines might be required to interrupt higher current as compared to long lines. For instance, as can be seen in Fig. 8 b), the current in $\mathrm{CB}_{21}$ reaches almost $5.6 \mathrm{kA}$ with unidirectional strategy while it does not exceed $3.9 \mathrm{kA}$ in $\mathrm{CB}_{12}$ in the bidirectional strategy (see Fig. 8 a)). Note that the length of line $\mathrm{L}_{12}$ is $100 \mathrm{~km}$. On the other hand, for line $\mathrm{L}_{13}$ $(200 \mathrm{~km})$, the current in $\mathrm{CB}_{31}$ reaches almost $3.8 \mathrm{kA}$ with unidirectional strategy and it reaches almost $4 \mathrm{kA}$ in $\mathrm{CB}_{13}$ in the bidirectional strategy (see Fig. 8.c) and (d)). The bus fault is cleared in longer time in communication-based unidirectional strategy as compared to the bidirectional strategy. Fig. 13 a) provides a comparison between the maximum interrupted current of different DCCBs during the DC bus and corresponding transmission line faults. As shown in the figure, the DCCBs are required to interrupt higher fault current during the line fault as compared to the DC bus fault in communication-based unidirectional protection strategy. Results of this study imply that the communication-based unidirectional scheme does not necessarily require DCCBs with higher current rating. Despite longer fault detection and trip times in the communicationbased unidirectional scheme, the cable inductance and the DCCB current limiting inductor limit the rate of rise of fault current in the remote DCCB.

2) Overcurrent-based method: As can be seen in Fig. 8 the current in $\mathrm{CB}_{21}, \mathrm{CB}_{31}$ and $\mathrm{CB}_{41}$ reach higher value in 

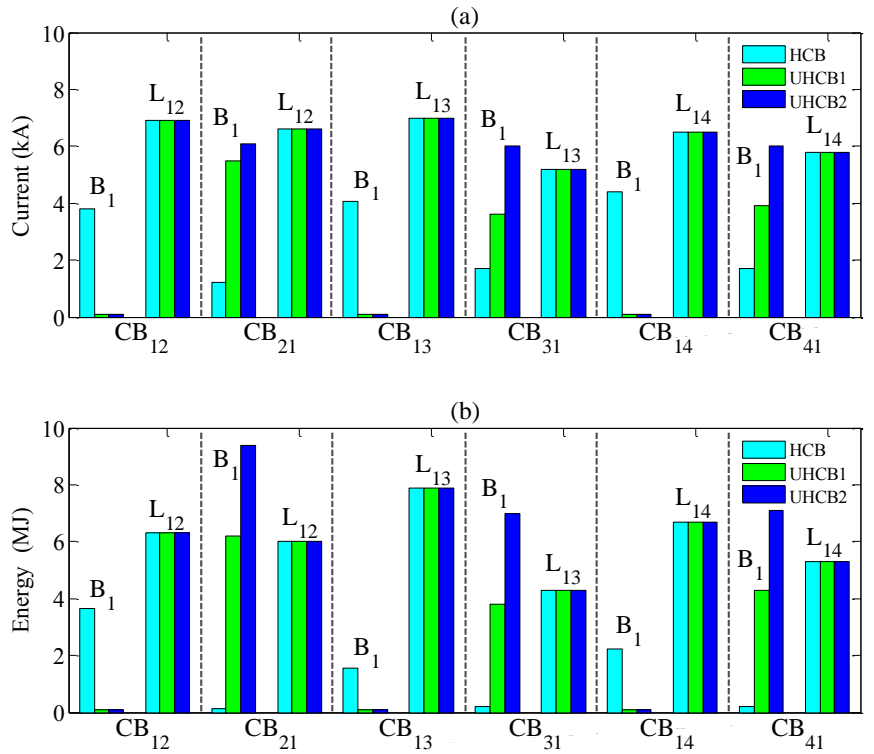

Fig. 13. (a) Maximum interrupted current and (b) absorbed energy in different DC circuit breakers during DC bus and line faults

overcurrent-based unidirectional scheme as compared to the current in $\mathrm{CB}_{12}, \mathrm{CB}_{13}$ and $\mathrm{CB}_{14}$ in the bidirectional and the communication-based unidirectional schemes. The overcurrent protection threshold may be set to lower values in order to shorten the fault identification time if it is coordinated with the non-unit protection scheme. As shown in Fig. 13 a), the maximum interrupted current in $\mathrm{CB}_{31}$ and $\mathrm{CB}_{41}$ is slightly higher for the DC bus fault with overcurrent-based method as compared to the maximum interrupted current for corresponding transmission line faults. Hence, the UHCBs might be required to interrupt higher current as compared to the $\mathrm{HCBs}$ depending on the overcurrent protection parameters.

\section{B. Surge arrester energy rating}

1) Communication-based method: The amount of absorbed energy in the surge arrester of DCCB depends on the interrupted current value and the fault location distance from the DCCB. The magnitude of interrupted current has higher impact on the amount of absorbed energy. The absorbed energy in surge arresters of DCCBs during the transmission line and the DC bus faults are compared in Fig. 13 (b). As can be seen, the surge arresters of UHCBs dissipate lower amount of energy during DC bus fault in communication-based unidirectional method as compared to corresponding transmission line fault. Note that the amount of absorbed energy in $\mathrm{CB}_{21}$ during bus fault is almost equal to the absorbed energy in $\mathrm{CB}_{12}$ during the line fault. These results imply that the energy rating of surge arresters for UHCBs with communication-based unidirectional strategy is not necessarily different than their energy rating for HCBs with the bidirectional strategy.

2) Overcurrent-based method: Due to the higher fault current during the DC bus fault in overcurrent-based method, the surge arresters dissipate higher amount of energy as compared to the line fault conditions (see Fig. 13(b)). Hence, the surge arresters in UHCBs with overcurrent-based method are required to be rated for higher energy absorption as compared to the HCBs with the typical strategy.

\section{Impact on the converters}

As seen in Fig. 10, Fig. 11 and Fig. 12, MMC 2 arm currents reach higher values as compared to the arm currents of other MMCs. MMC 2 is connected to the faulted bus $\left(B_{1}\right)$ through a $100 \mathrm{~km}$ cable, which is shorter than other adjacent cables. Therefore, MMC 2 is more influenced by the fault transient as compared to the other MMCs. Furthermore, as can be seen in Fig. 12(a), one of MMC 2 arm currents reaches almost $3 \mathrm{kA}$, which would be higher than self-protection threshold level of MMC. Although in this study MMC 2 is not blocked, the application of unidirectional protection strategy may cause blocking of the MMCs connected to the faulted bus by a short transmission line. This issue can be avoided by either slight increase in the inductance of DCCBs limiting inductor or using IGBTs with higher current capability in MMCs.

\section{Impact on $D C C B$}

The MBU and LCS in the UHCB requires half the number of semiconductors as compared to the HCBs. For instance, an $\mathrm{HCB}$ with $320 \mathrm{kV}$ and $9 \mathrm{kA}$ voltage and current ratings requires 1416 IGBTs with $3.3 \mathrm{kV}$ voltage rating in the MBU [7]. By applying unidirectional protection strategy this number can be reduced to 708 by mean of the UHCB. Due to the large number of required IGBTs by the HCB and considering the peripheral circuits and elements for each IGBT, this reduction can significantly decrease the initial investment for implementation of the HCBs.

\section{FINAL REMARKS}

The UHCBs show technical and economic advantages thanks to their less initial and operational costs as compared to the typical HCBs. A unidirectional protection strategy for MT-HVDC grid is suggested in this paper. The results of study confirm that the unidirectional protection strategy can be utilized for protection of the MT-HVDC grid.

Two methods for remote DCCB tripping are considered: 1) communication-based and 2) overcurrent-based methods. The communication-based method shows better performance as compared to the overcurrent-based method.

The results of comparison study for different parameters of DCCBs imply that the current rating of DCCBs and the size of surge arresters are not necessarily different for the bidirectional and unidirectional strategies. However, the impact of suggested strategy on all converters of the grid, particularly the converters with shorter transmission line between them should be analyzed. In order to avoid blocking of the MMCs at healthy buses, slight increase in DCCB limiting inductor size or current rating of MMC's IGBTs might be required. Application of unidirectional protection strategy may significantly reduce the number of required semiconductor switches in the MBU of HCBs. Considering the large number of required semiconductor switches by the $\mathrm{HCB}$ and also the peripheral circuits and elements of each semiconductor switch, this reduction can significantly decrease the initial investment for implementation of the HCBs. 
APPENDIX

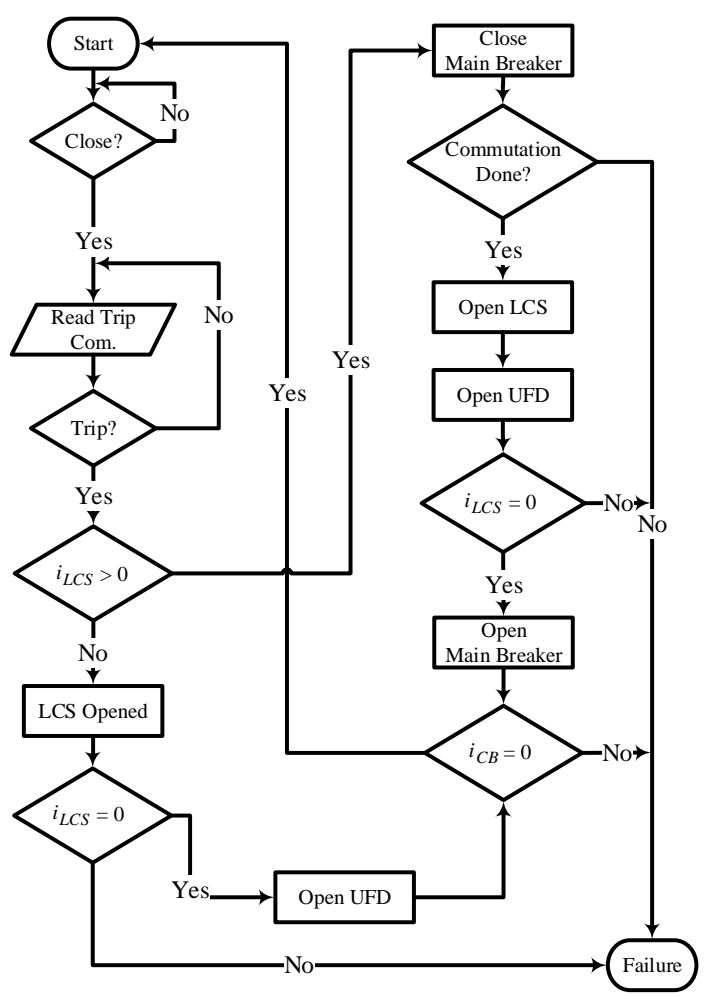

Fig. 14. Unidirectional hybrid DC circuit breaker operation logic flowchart

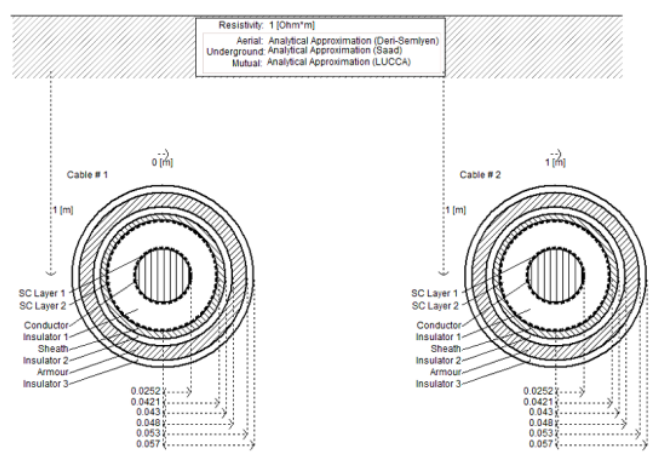

Fig. 15. Cross-section and configuration of the XLPE insulated HVDC cable

TABLE II

Four-Terminal HVDC System PARAMETERS [14]

\begin{tabular}{lcc}
\hline \hline Parameter & Converter 1, 2, 3 & Converter 4 \\
\hline Rated power & $900 \mathrm{MVA}$ & $1200 \mathrm{MVA}$ \\
AC grid voltage & $400 \mathrm{kV}$ & $400 \mathrm{kV}$ \\
Converter AC voltage & $380 \mathrm{kV}$ & $380 \mathrm{kV}$ \\
Transformer, $u_{k}$ & $0.15 \mathrm{pu}$ & $0.15 \mathrm{pu}$ \\
Arm capacitance $C_{\text {arm }}$ & $29.3 \mu \mathrm{F}$ & $39 \mu \mathrm{F}$ \\
Arm reactor $L_{\text {arm }}$ & $84.8 \mathrm{mH}$ & $63.6 \mathrm{mH}$ \\
Arm,resistance $R_{\text {arm }}$ & $0.885 \Omega$ & $0.67 \Omega$ \\
Bus filter reactor $L_{s}$ & $10 \mathrm{mH}$ & $10 \mathrm{mH}$ \\
\hline
\end{tabular}

TABLE III

DC CABLE DATA [15]

\begin{tabular}{lcccc}
\hline \hline Layer & $\begin{array}{c}\text { Radius } \\
(\mathbf{m m})\end{array}$ & $\begin{array}{c}\text { Resistivity } \\
(\mathbf{m})\end{array}$ & $\begin{array}{c}\text { Rel. } \\
\text { permeability }\end{array}$ & $\begin{array}{c}\text { Rel. } \\
\text { permittivity }\end{array}$ \\
\hline (1) Core & 25.2 & $1.72 \times 10^{-8}$ & 1 & 1 \\
(2) Insulator & 40.2 & - & 1 & 2.3 \\
(3) Sheath & 43.0 & $2.20 \times 10^{-7}$ & 1 & 1 \\
(4) Insulator & 48.0 & - & 1 & 2.3 \\
(5) Armor & 53.0 & $1.80 \times 10^{-7}$ & 10 & 1 \\
(6) Insulator & 57.0 & - & 1 & 2.1 \\
\hline
\end{tabular}

\section{REFERENCES}

[1] N. Chaudhuri, B. Chaudhuri, R. Majumder, and A. Yazdani, Multiterminal direct-current grids: Modeling, analysis, and control. John Wiley \& Sons, 2014

[2] A. Mokhberdoran and A. Ajami, "Symmetric and asymmetric design and implementation of new cascaded multilevel inverter topology," IEEE Transactions on Power Electronics, vol. 29, no. 12, pp. 6712-6724, Dec 2014.

[3] A. Mokhberdoran, A. Carvalho, N. Silva, H. Leite, and A. Carrapatoso, "Application study of superconducting fault current limiters in meshed hvdc grids protected by fast protection relays," Electric Power Systems Research, vol. 143, pp. $292-302,2017$.

[4] A. Mokhberdoran, A. Carvalho, H. Leite, and N. Silva, "A review on hvdc circuit breakers," in Renewable Power Generation Conference (RPG 2014), 3rd, Sept 2014, pp. 1-6.

[5] J. Häfner and B. Jacobson, "Proactive hybrid hvdc breakers - a key innovation for reliable hvdc grids," in Electric system of the future Integrating supergrids and microgrids international symposium, Italy, Sept 2011, pp. 1-8.

[6] B. Geebelen, W. Leterme, and D. V. Hertem, "Analysis of dc breaker requirements for different hvdc grid protection schemes," in $A C$ and $D C$ Power Transmission, 11th IET International Conference on, Feb 2015, pp. 1-7.

[7] G. Liu, F. Xu, Z. Xu, Z. Zhang, and G. Tang, "Assembly hvdc breaker for hvdc grids with modular multilevel converters," IEEE Transactions on Power Electronics, vol. PP, no. 99, pp. 1-1, 2016.

[8] K. Sano and M. Takasaki, "A surgeless solid-state dc circuit breaker for voltage-source-converter-based hvdc systems," IEEE Transactions on Industry Applications, vol. 50, no. 4, pp. 2690-2699, July 2014.

[9] A. Mokhberdoran, A. Carvalho, N. Silva, H. Leite, and A. Carrapatoso, "A new topology of fast solid-state hvdc circuit breaker for offshore wind integration applications," in Power Electronics and Applications (EPE'15 ECCE-Europe), 2015 17th European Conference on, Sept 2015, pp. $1-10$.

[10] D. Jovcic, M. Taherbaneh, J. P. Taisne, and S. Nguefeu, "Offshore dc grids as an interconnection of radial systems: Protection and control aspects," IEEE Transactions on Smart Grid, vol. 6, no. 2, pp. 903-910, March 2015.

[11] S. P. Azad and D. V. Hertem, "A fast local bus current-based primary relaying algorithm for hudc grids," IEEE Transactions on Power Delivery, vol. PP, no. 99, pp. 1-1, 2016.

[12] A. Hassanpoor, J. Häfner, and B. Jacobson, "Technical assessment of load commutation switch in hybrid hvdc breaker," IEEE Transactions on Power Electronics, vol. 30, no. 10, pp. 5393-5400, Oct 2015.

[13] A. Mokhberdoran, N. Silva, H. Leite, and A. Carvalho, "A directional protection strategy for multi-terminal vsc-hvdc grids," in 2016 IEEE 16th International Conference on Environment and Electrical Engineering (EEEIC), June 2016, pp. 1-6.

[14] W. Leterme, N. Ahmed, J. Beerten, L. Angquist, D. V. Hertem, and S. Norrga, "A new hudc grid test system for hude grid dynamics and protection studies in emt-type software," in $A C$ and DC Power Transmission, 11th IET International Conference on, Feb 2015, pp. 1-7.

[15] F. Mura, C. Meyer, and R. W. D. Doncker, "Stability analysis of highpower dc grids," IEEE Transactions on Industry Applications, vol. 46, no. 2, pp. 584-592, March 2010.

[16] S. C. F. Behrouz A. Forouzan, Data Communications and Networking. McGraw-Hill Forouzan Networking, 2007. 